University of Cambridge, which treated the coding of signals in sensory mechanisms. There is evidence of mechanisms operating at low levels in sensory pathways to reduce the amount of redundancy in the vast number of parallel information channels. Unlike the recoding proposed by Shannon for communication channels, the aim is not to remove all redundancy, but to reduce the number of pulses on any given channel, and to reduce correlation between channels. For two binary channels, the specification of such a coding devico is very simple, and a model of this device was shown in the exhibition.

Among the specialized topics discussed was automatic programming, to which a morning's session was devoted. Dr. Grace Hopper, of Remington Rand, Ltd., gave the opening paper, and the session was rounded off by a paper from Dr. A. P. Ershov, of the Academy of Sciences of the U.S.S.R.

An afternoon's session was devoted to mechanical language translation, and Dr. Ershov, at short notice, said something about the groups working on this subject in the U.S.S.R.

Unusual fields for mechanization formed the subject of several papers. Dr. L. Mehl, of the École Nationale d'Administration, Paris, spoke on automation in the legal world. He described a machine for retrieving legal information and a machine for legal argument. The limitations of such machines are that they are incapable of evaluating data, or of developing the principle of law, so they cannot be a substitute for the jurist.

Dr. F. Paycha, of Paris, spoke about the logical structure of medical diagnosis, emphasizing the vast volume of facts on which it is based, and the need for mechanization to reduce the chance of an error. In the discussion which followed, the question was raised of how far probability considerations should be allowed to influence diagnosis.

Speech recognition was the subject of two papers. Prof. D. B. Fry and Mr. P. Denes, both of University
College, London, described how linguistic information has been brought into the problem of speech recognition. A machine capable of handling 13 English phonemes and using digram frequencies to make a decision was shown in the exhibition. A paper by Mr. P. Ladefoged, of the University of Edinburgh, reviewed the whole field of speech perception, making the particular point that speech is not, in any sense, a sequence of small discrete elements.

In the analogous field of visual pattern recognition, a paper was read by Dr. W. K. Taylor, of University College, London.

Other papers dealt with literature searching, the mechanization of administration, and learning in animals, in addition to the subjects mentioned above.

The general impression given by the symposium was that in none of the fields of study is there any finality as to the basic approach to the problem. In the field of intelligent machines, there was a wealth of suggestions, but none of these has yet reached the stage of a successful test. It was also evident that many suggestions that can be made for machines to solve problems or perceive patterns may fail because the number of individual units in the machine is too large and that any practical machine must include some trick to achieve economy of equipment.

The modern theory of automata began with A. M. Turing's proof that universal computing machines were possible. Dr. Turing's ideas, and those of J. von Neumann, led to the construction of electronic computers, which are the working tools of the experimental approach to artificial intelligence. It seems possible that a further great advance in the development of intelligent machines will soon be made.

The Proceedings of the symposium, including the papers read, together with the discussion, will be published by H.M. Stationery Office in due course. D. W. Davies

\title{
DEVELOPMENT OF ELECTRIC CABLES
}

$\mathrm{M}$ R. S. E. GOODALL delivered his presidential address before the Institution of Electrical Engineers on October 9. His subject was electric cables, and a substantial part of his address was devoted to reviewing the history of their development.

It was in the year 1812 that the first experiments were made in applying a soluble material, said to be india rubber, to the insulation of copper wires. The great initial development of the electric telegraph took place as a means of inland communication and the circuits employed were almost wholly composed of overhead, open-wire, lines. It was the timely discovery of the excellent properties of gutta percha as an insulant and its practical application to electric cables by Werner Siemens that initiated the development of submarine telegraph cables and indeed of cables generally. The year 1851 saw the first crossChannel cable in operation, and fifteen years later the first successful telegraph cable spanned the Atlantic Ocean. The pioneer of the electric power cable was Sebastian de Ferranti. The transmission of power by alternating current at 10,000 volts from the Central Station at Deptford to the West End of London was effected by concentric cables of entirely novel design. Oil-impregnated paper was the dielectric, and the type of construction devised by Ferranti remained the basis of high-voltage power cable design for half a century. By 1900 single-core and three-core impregnated paper lead-sheathed cables were in regular manufacture in Britain.

The manufacture of telephone cables developed rapidly from about 1890 . Multi-circuit lead-covered cables when first introduced were filled with insulating material such as paraffin wax, but their electrical characteristics were soon greatly improved by the adoption of the dry-core technique, in which advantage is taken of the air interstices to obtain lower electrostatic capacitance. The first cables used for longdistance telephony were simply adaptations of telegraph cables and used gutta percha as a dielectric. For gutta percha, balata was later substituted and this held the field for submarine purposes until comparatively recently.

Two very important developments in high-voltage power cables occurred during the 1920's. The major factor tending to initiate breakdown in highvoltage cables had been traced to ionization in voids 
in the dielectric, and the formation of voids had been demonstrated to be associated with the thermal expansion and contraction of cables under varying conditions of load. Improved design and better techniques of impregnation proved to be insufficient to remove the inherent electrical weakness resulting from heating cycles. The first effective remedy was devised by Emanueli, who, in 1920, employed a thin mineral oil as a liquid impregnant applied under pressure from reservoirs at predetermined points in the cable system. An alternative method of suppressing ionization in voids, invented at about the same time, was the use of an inert gas at high pressure. This development did not proceed very rapidly and was seriously interrupted by the Second World War. There are, however, now many important installations of super-tension gas pressure cables.

The distribution of electricity in buildings was first effected by wires insulated with paraffined cotton, but it was not long before rubber was adopted as the insulant. Some indication of the early rate of development of the distribution of electricity to domestic and industrial premises is given by the fact that in 1882 the Society of Telegraph Engineers and Electricians issued their first "Rules and Regulations for the Prevention of Fire Risks from Electric Lighting".

Although the techniques of cable manufacture were being steadily developed and improved, there had been, up to the outbreak of the Second World War, little change in the basic materials and processes. During the Second World War and since, very farreaching changes have taken place. Plastics and synthetic rubbers have been introduced, some of these materials having excellent electrical characteristics together with satisfactory mechanical properties, and a substantial proportion of the electric cables now manufactured employ these new insulants. It was the development of radar during the Second World War that evoked the urgent demand for cables which would transmit satisfactorily very highfrequency currents, and polythene was the material which enabled this demand to be met. The drastic reduction in the available supplies of natural rubber which developed as the War progressed was the incentive in the search for synthetic substitutes. Polyvinyl chloride, commonly known as P.V.C., is a war-time product which is now firmly established in cable-making practice.

In addition to the introduction of new insulating materials there have been, since the end of the War, important developments in manufacturing methods. As an examplo of this may be cited the new method of coating wires known as continuous vulcanization. A well-established method of applying the rubber covering to wires involves the continuous interleaving of a group of wires moving longitudinally in parallel between two thin ribbons of rubber. The passage of this layered ribbon between suitably grooved rollers produces individual insulated wires with, of course, seamed coverings. The modern alternative to this is known as continuous vulcanization.

In this process rubber compound is forced on to the wire as a seamless cylindrical coating in the extruding 'head' of a rotary-screw extrusion machine through which the wire is passing at fairly high speed. Immediately on leaving the head the covered wire is passed into a long well-lagged steel tube which contains high-pressure steam, and in this vulcanization takes place. In this process the finished core is produced to very close tolerances by the extensive utilization of electronic methods of automatic control.

Direct extrusion methods are employed for the covering of cables insulated with polyvinyl chloride and polythene. It is not practicable to use, for these synthetic materials, the same machines as are used for natural rubber coatings, but plants designed for polyvinyl chloride can with relatively slight modification be utilized for polythene.

Some important advantages, other than those of improved electrical characteristics, are associated with the use of the new plastics, but there are also limitations.

Polyvinyl chloride has good mechanical properties and, in addition, is strongly resistant to corrosion. For this reason it is used as an external, serving to protect from the corrosive effects of soil waters or of acids such as those produced when textile servings rot through bacterial attack. Wire insulated with polyvinyl chloride or polythene, however, is not capable of withstanding as great an electrical overload as can be tolerated by conductors insulated with vulcanized indiarubber. Ordinary grades of polythene melt at a temperature slightly above $105^{\circ} \mathrm{C}$. Polyvinyl chloride, while it has no sharp melting point, becomes softer as the temperature increases and may suffer severe deformation under mechanical stress. The thermal characteristics of polythene can be considerably improved by exposing the material to neutron or electron bombardment. Such treatment effects cross-linkage between the molecular chains in its structure. This eliminates the sharp melting-point and the material becomes rubber-like at about $150^{\circ} \mathrm{C}$. Irradiation is, however, expensive, and it appears unlikely that irradiated polythone will be available except for special applications.

Another important synthetic material is silicone. rubber. This material will operate indefinitely at $150^{\circ} \mathrm{C}$. and flexibility is retained down to $-70^{\circ} \mathrm{C}$. Its electrical properties are similar to those of natural rubber. Cables insulated with silicone-rubber have the unique property that, if exposed to fire, the residue of the insulation is largely pure silica, and after a fire such cables can be operated temporarily provided they are not disturbed.

Mr. Goodall's address ended with a brief review of the technical possibilities and objectives of cable making in Great Britain. The trend towards greater use of plastic materials would, he thought, undoubtedly continue, and there would probably be continued effort towards such reductions of dimensions as might be rendered possible by improved process control methods.

To be able to face intensifying competition from abroad both in the home and export markets, the industry must be prepared to face the consequences of rationalization of production, with consequent regrouping of manufacture and co-operation in one form or another among the different companies concerned. Cable users, on the other hand, must be prepared, in their own and in the national interest, to accept some measure of restriction of choice. The two bugbears of eable making are alternatives and variety, and the industry as a whole possesses surplus plant for many operations, although fow if any of these operations are wholly obsolete. In effect, standardization must be directed towards the elimination of unnecessary complication rather than the inclusion of all the variants for which there might be a demand.

JAMES GREIG 